\title{
A Unique Case of Bilateral Synchronous Testicular Tumor with Concomitant Bilateral Diffuse Intratubular Germ Cell Neoplasia: Testis Sparing Surgery and Local Radiotherapy
}

\author{
Mehmet B. Yuksel $^{\mathrm{a}} \quad$ Bilal Gumus $^{\mathrm{a}} \quad$ Erdem Özbek $^{\mathrm{a}} \quad$ Nalan Nese $^{\mathrm{b}}$ \\ Department of a Urology and 'Pathology, Faculty of Medicine, Celal Bayar University, Manisa, Turkey
}

\section{Key Words}

Sycnhronous bilateral testis tumor - Intratubular germ cell neoplasia $\cdot$ Testis sparing surgery $\cdot$ Local radiotherapy

\begin{abstract}
Synchronous bilateral testicular germ cell tumors (TGCTs) are seen in exteremely rare cases. Although there is still no standard therapy for bilateral TGCTs, bilateral orchiectomy is recommended as the gold standard treatment. Nevertheless, it has some long-term problems, such as infertility and psychosocial difficulties, and thus some clinicians prefer to perform testis-sparing surgery in appropriate cases. We reviewed the first case of bilateral synchronous TGCT with concomittant bilateral diffuse intratubular germ cell neoplasia in a young single patient, who was treated by a left radical orchiectomy and right testis sparing-surgery with following local radiotherapy to the right residual testicular tissue with previous semen cryopreservation to maintain the ability to father children. We supposed that testis-sparing surgery can be a feasible therapeutic alternative to radical orchiectomy in patients with bilateral TGCTs in terms of improving the quality of life and continuing fertility and normal hormonal status with no medications. However, while the long-term effects are not yet known, this type of treatment should be perpormed in carefully selected cases with longlife expectancy.
\end{abstract}

Copyright $\odot 2012$ S. Karger AG, Basel

\section{KARGER}

Fax +4161306 1234

E-Mail karger@karger.ch

www.karger.com
(C) 2012 S. Karger AG, Basel

1015-9770/12/0063-0165\$26.00/0

Accessible online at:

www.karger.com/cur

\section{Introduction}

Testicular germ cell tumors (TGCTs) are commonly unilateral, but bilateralism is also possible for TGCTs with an incidence of $1-5 \%[1,2]$. According to some literature, the vast majority of bilateral TGCTs occur metachronously. However, synchronous bilateral tumors were also reported in rare cases [1-3]. In this study, we reviewed a unique case of bilateral synchronous TGCT with concomittant bilateral diffuse intratubular germ cell neoplasia (ITGCN) in a young single patient, which was treated by a left radical orchiectomy and right testis-sparing surgery with following local radiotherapy to the right residual testicular tissue with previous semen cryopreservation to maintain the ability to father children.

\section{Case Report}

A 23-year-old single male presented with a painless left testicular swelling that occurred in the last 3-4 days. There were no associated constitutional symptoms and no history of trauma, infection or a bleeding disorder. Physical examination revealed a left testis that was irregularly enlarged with discrete masses $2-3$ $\mathrm{cm}$ in size, and at palpation it had no pain or tenderness. Bilateral spermatic cords, scrotum and contralateral testis were normal. No enlarged lymph node was palpable. Scrotal ultrasonography revealed bilateral heterogeneous testicular masses (fig. 1). Computerized tomography of the abdomen and thorax was negative for lymphadenopathy or metastases. Preoperative increased tumour
Mehmet Bilgehan Yuksel

Department of Urology, Faculty of Medicine

Celal Bayar University

Manisa (Turkey)

E-Mail drmehmetyuksel@hotmail.com 


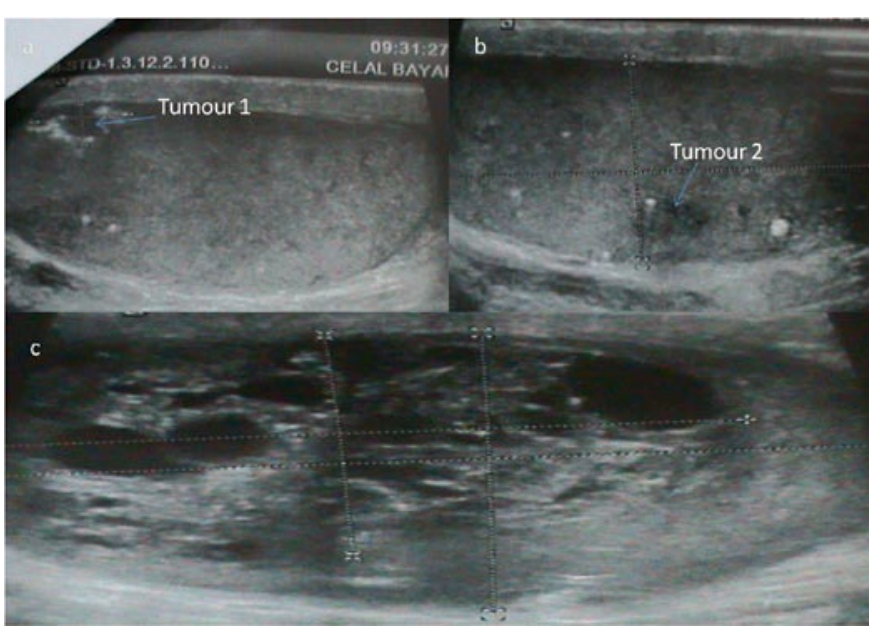

Fig. 1. Ultrasonographical images of tumors on both sides. $\mathbf{a}, \mathbf{b}$ Right testis and localized tumor $(8 \times 4 \mathrm{~mm}$ and $11 \times 3 \mathrm{~mm}$ in size and limited in superoanterior and posteroinferior locations of right testis); c Left testis and large tumor with solid and cystic areas (39 $\times 23 \mathrm{~mm}$ sized mass containing solid and cystic areas).

markers were: alpha fetoprotein (AFP) $25.9 \mathrm{ng} / \mathrm{ml}$, beta human chorionic gonadotropin ( $\beta$-HCG) $18.41 \mathrm{mIU} / \mathrm{ml}$ and LDH 250 IU/l. While a radical orchiectomy was performed for the left testis, a right partial orchiectomy including the local excision of two testicular masses provided a surgical specimen in $1.5 \mathrm{~cm}$ diameter (fig. 2). Furthermore, local excisional biopsies was taken from surgical margins and the tumor base. The frozen section analysis of biopsies was declared diffuse ITGCN without any evident residual tumors.

At the pathological evaluation, the left radical orchiectomy material macroscopically showed a $4 \times 5 \times 2 \mathrm{~cm}$ white-grey solidcystic tumor mass, which occupied the entire specimen. Microscopically a diagnosis of a mixed nonseminomatous TGCT was determined, comprised of $80 \%$ teratoma, $10 \%$ embryonal carcinoma and $10 \%$ yolk sac tumor. The tumor was well limited in the testis and did not invade peritesticular tissues and the spermatic cord. Although no lymphovascular invasion was observed, diffuse ITGCN was present in the periphery of the tumor (T1N0M0S1IS). The pathological analysis of right testis sparing surgical specimen showed a diagnosis of embryonal carcinoma with diffuse ITGCN in the periphery and at the base of the tumors. No lymphovascular invasion was present (T1N0M0S1IS). Although surgical margins were without any evident tumors on both sides, the presence of diffuse ITGCN at the base and around the periphery of the surgical area required subsequent local radiotherapy to the right residual testicular tissue (fig. 3).

The patient was young and declared the expectation of being able to father children, and thus cryopreservation including 2 semen samples was performed. After semen cryopreservation, the treatment was followed by subsequent local radiotherapy to the testis. The patient was referred to a private oncology center for the radiotherapy treatment.

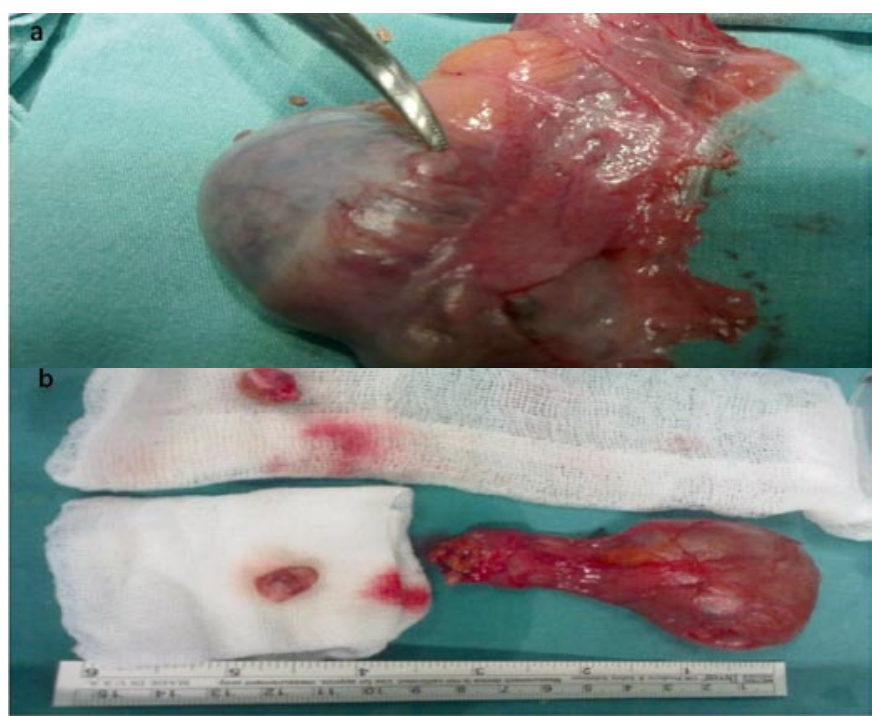

Fig. 2. a Right testis and a localized tumor; b Two locally excised right tumor specimens and left radical orchiectomy material.

After the surgery, we followed the patient by laboratory and radiological analyses. At postoperative day 10, tumor markers regressed to the normal values of: AFP $4.19 \mathrm{ng} / \mathrm{ml}, \beta$-HCG $0-1$ $\mathrm{mIU} / \mathrm{ml}$ and LDH $121 \mathrm{IU} / \mathrm{l}$. It was found that those were in the normal range. Modarate hepatomegalia and hepatosteatosis, nonpathological lymph nodes with a diameter of $<5-6 \mathrm{~cm}$ and no other significant pathologies were determined in the abdomen by computerized tomography at postoperative 6 months. Biochemical and hematological markers and lung radiography were also normal.

\section{Discussion}

Bilateral orchiectomy is recommended as the gold standard treatment for patients with bilateral TGCTs. The increased survival may cause psychosocial difficulties. Therefore, some clinicians perform a testis-sparing approach to avoid these problems $[4,5]$. While the longterm effects are not yet known, this type of surgery can be recommended especially in a young patient with long life expectancy and where hormonal or fertility concerns are present, and when the tumor size is less than $2 \mathrm{~cm}$ [6].

In our study, the patient was a young, fertile male with the diagnosis of synchronous bilateral TGCT without any risk factors, and the right sided mases were also small in size and limited to the testis. Thus, we performed a 


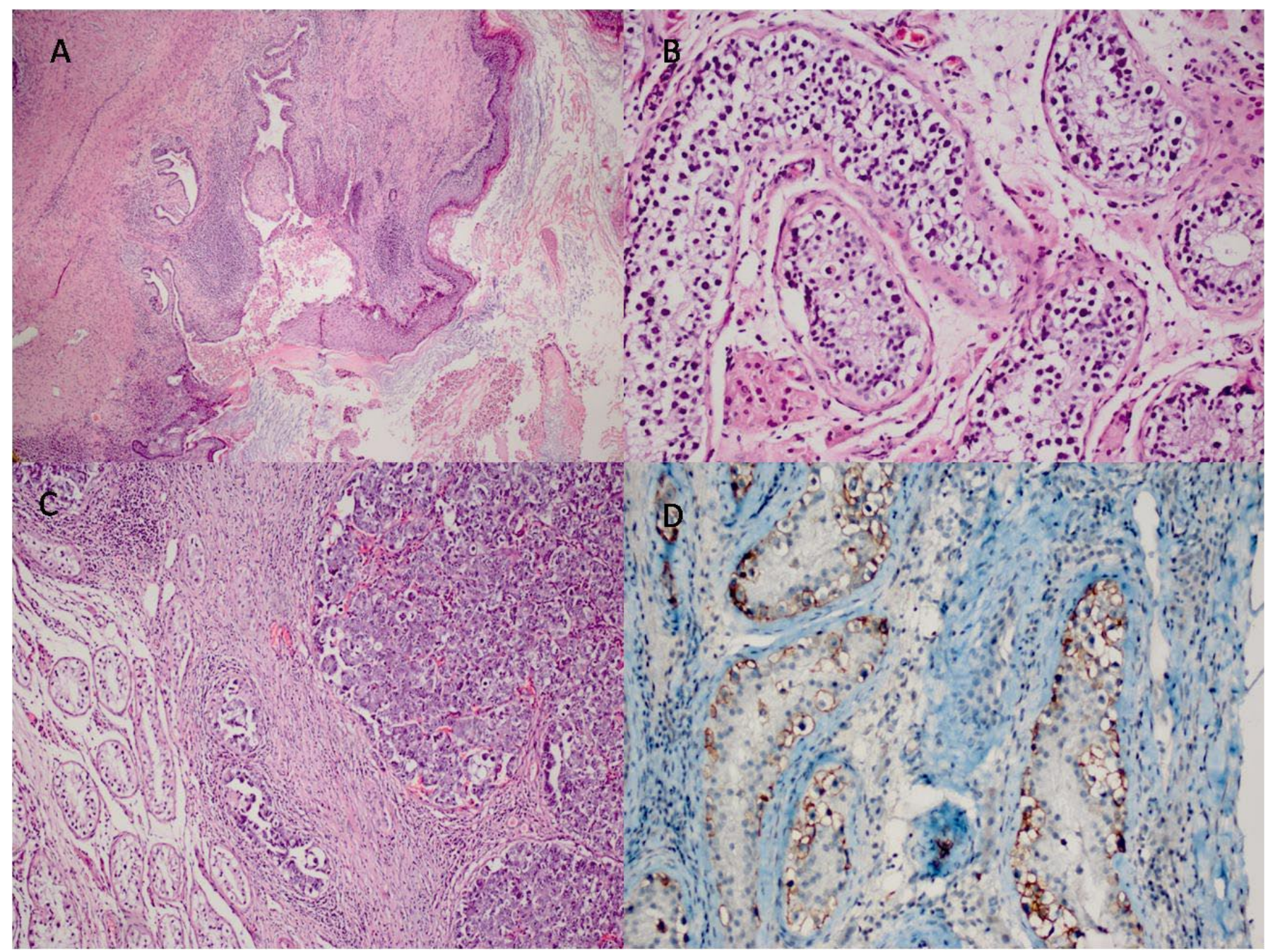

Fig. 3. The demonstration of histopathological images. A Teratoma areas in the right testis tumor $(\mathrm{HE} \times 40)$; B Intratubuler germ cell neoplasia, unclassifiable at the periphery of the right testicular mass $(\mathrm{HE} \times 100)$; C Embryonal carcinoma characterized by glandular and solid areas in the left testis $(\mathrm{HE} \times 100)$; D Intratubuler germ cell neoplasia, unclassifiable at the periphery of the left testicular mass (PLAP $\times 200)$.

right testis-sparing surgery including local excision of two small and limited mases in the testis and a left radical orchiectomy where the large mass that occupied the entire testis. When the frozen section showed no evident residual tumors, diffuse ITGCN was determined in the right residual testicular tissue. At postoperative 10th day control, although the pathological analysis revealed the diagnosis of a mixed nonseminomatous TGCT on the right side and a diagnosis of embryonal carcinoma on the left side with tumor-free surgical margins and normal postoperative tumor markers, diffuse ITGCN was present on both pathological specimens. The presence of diffuse ITGCN with tumor-free surgical margins in the right residual testicular tissue changed the subsequent management procedure.

A particular problem in the treatment of TGCT is that $80 \%$ of testes containing a TGCT also contain a concomittant ITGCN in the non-tumor part of the testis [7, 
8]. Untreated testis ITGCN goes on to become invasive carcinoma in $70 \%$ of cases within 7 years [8]. The recommended treatment for the testis ITGCN is local irradiation with 20 Gy to the residual testis after partial orchiectomy or to the contralateral testis where biopsy has shown ITGCN after unilateral orchiectomy for TGCT [9]. However, radiotherapy can cause infertility, therefore the patient must be carefully counseled before radiotherapy. If the patient has the expectation of fathering children, radiotherapy can be delayed [10].

After a detailed discussion with the patient on treatment alternatives and possible risks, we planned an urgent local radiotherapy to the testis. Although we had the choice of delaying radiotherapy, the patient did not prefer this choice of treatment. Therefore, we performed semen cryopreservation to maintain fertility previously to radiotherapy and a following radiotherapy to avoid tu- mor progression during the waiting period. The semen samples had normal features for fathering children. After local radiotherapy, the treatment was completed and the patient underwent classical follow-up procedure.

\section{Conclusion}

Synchronous bilateral TGCTs are seen in exteremely rare cases. There is still no standard therapy for bilateral TGCT and each patient requires individual therapeutic management. We supposed that this was the first case of synchronous bilateral TGCT containing concomittant diffuse ITGCN on both sides, which was treated by a left radical orchiectomy and a right testis-sparing surgery containing a following local radiotherapy to the residual testicular tissue with previous semen cryopreservation.

\section{References}

-1 Akdogan B, Divrik RT, Tombul T, Yazici S, Tasar C, Zorlu F, Ozen H: Bilateral testicular germ cell tumors in Turkey: increase in incidence in last decade and evaluation of risk factors in 30 patients. J Urol 2007;178:129133.

2 Che M, Tamboli P, Ro JY, Park DS, Ro JS, Amato RJ, Ayala AG: Bilateral testicular germ cell tumors: twenty-year experience at M.D. Anderson Cancer Center. Cancer 2002; 95:1228-1233.

>3 Klatte T, de Martino M, Arensmeier K, Reiher F, Allhoff EP, Klatte D: Management and outcome of bilateral testicular germ cell tumors: a 25-year single center experience. Int J Urol 2008;15:821-826.
-4 Heidenreich A, Holtl W, Albrecht W, Pont J, Engelmann UH: Testis-preserving surgery in bilateral testicular germ cell tumours. Br J Urol 1997;79:253-257.

$\checkmark 5$ Haulgatte A, De La Taille A, Fournier R, Goluboff ET, Camporo P, Houdelette P: Paternity in a patient with seminoma and carcinoma in situ in a solitary testis treated by partial orchiectomy. BJU Int 1999;84:374-375.

-6 Demir A, Onol FF, Eren F, Turkeri L: Testis-sparing surgery in an adult with bilateral synchronous seminomatous tumor. Int J Urol 2004;11:1142-1144.

$>7$ Krege S, Souchon R, Schmoll HJ: Interdisciplinary consensus on diagnosis and treatment of testicular germ cell tumors: result of an update conference on evidence-based medicine (EBM). Eur Urol 2001;40:372-391.
-8 Dieckmann KP, Skakkebaek NE: Carcinoma in situ of the testis: review of biological and clinical features. Int J Cancer 1999;83:815822.

9 Giwercman A, von der Maase H, Rorth M, Skakkebaek NE: Current concepts of radiation treatment of carcinoma in situ of the testis. World J Urol 1994;12:125-130.

10 Classen J, Dieckmann K, Bamberg M, Souchon R, Kliesch S, Kuehn M, Loy V: Radiotherapy with 16 Gy may fail to eradicate testicular intraepitelial neoplasia: prelaminary communicationof a dose-reduction trial of the German Testicular Cancer Study Group. Br J Cancer 2003;88:828-831. 